\title{
THE THEORETICAL AND METHODICAL APPROACH TO AN ASSESSMENT OF A LEVEL OF DEVELOPMENT OF THE ENTERPRISE IN CONDITIONS OF GLOBALIZATION
}

\author{
Tatiana SHVED 1 , \\ National University of Food Technologies, Ukraine
}

\begin{abstract}
The subject of this article is theoretical, methodical and practical aspects of enterprise development in conditions of globalization. The purpose of this research is to provide theoretical and methodical approach to an assessment of a level of development of the enterprise, which is based on the relationship between the factors and influence, illustrating the effect of the internal and external environment of enterprises functioning, and indicates the level of development of the enterprise. Methodology. Theoretical basis of the study was the examination and rethinking of the main achievements of world and domestic science on the development of enterprises. To achieve the objectives of the research following methods were used: systemic and structural analysis for the formation of methodical approaches to the selection of the factors, influencing the development of enterprises; abstract and logical - for the formulation of conclusions and proposals; the method of valuation and expert assessments to the implementation of the proposed theoretical and methodical approach to an assessment of a level of development of the enterprise in conditions of globalization. Results of the research is the proposed theoretical and methodical to an assessment of a level of development of the enterprise in conditions of globalization, which is associated with the idea of development of the enterprise as a system with inputs-factors, influencing on the development, and outputs - indicators of the level of enterprise development within these factors. So, the chosen factors - resources, financial-economic activity, innovation and investment activities, competition, government influence, and foreign trade. Indicators that express these factors, are capital productivity, labour productivity, material efficiency within the first factor; the profitability of the activity, the coefficient of current assets, the total liquidity coefficient, financial stability coefficient, the coefficient of Beaver within the second factor; the proportion of intangible assets, the coefficient of investment in the third factor; the market share of enterprises in total volume of industry's production in the fourth aspect; the coefficient of the tax burden under the fifth factor and the share of exports in total production in the last factor. Within this approach to avoid the different dimensions of the particular indicators illustrating the level of the enterprises development it's carried out their rationing. The importance of each factor influencing the level of development of the enterprise in conditions of globalization can be conducted through the use of expert research, verification of the representativeness of which is by using the coefficient of concordance to determine the level of consistency of experts' opinions and the criterion of Pearson, which confirms its importance. In the event of a sufficient consistency of opinion of experts have the ability to offer an integrated indicator of the level of development of the enterprise in conditions of globalization through the use of a common desirability function of Harrington. Assessment of a level of development of the enterprise in conditions of globalization for a particular industry is by using well-known scales of desirability, which is in the range from 0 to 1 and allows one to calculate the integral indicator and to determine the level of development as high, medium, low and critically low.
\end{abstract}

Key words: the level of development of the enterprise, globalization, indicators, factors affecting the development of enterprises, development strategy of the enterprise.

JEL Classification: L23, F61, C67, 012, L53

\section{1. Введение}

Угмубление интеграции социально-экономических систем отдельных государств в еАиное экономическое пространство, повышение конкуренции на внутренних и внешних рынках, ускорение научно-технического развития во всех сферах общественной Аеятельности предопределяют необходимость разработки и реализации качественных, своевременных, цеменаправценных

Corresponding author:

${ }^{1}$ Department of Economy and Law, National University of Food Technologies.

E-mail: shtv2008@mail.ru 
и системных решений в сфере управления произвоАством субъектов хозяйствования. Современный этап развития рыночных отношений требует от национальных преАприятий активных Аействий, направменных на повышение эффективности их функционирования. ОАнако, Аанная проблема явмяется неразрешенной без комплексной оценки уровня развития преАприятий. Последнее повышает актуальность исследования методических подходов к названной проблематике как А^я экономической науки, так и А^я практики. Теоретические и практические аспекты деятельности и развития преАприятий, проблемы оценки эффективности их функционирования были освещены в трудах таких ученых как: В. Андрийчук (Andriychuk, 2005), И. Гонтарева (Gontareva, 2012), А. Іванилов (Ivanilov, 2009), М. Мейер (Meyer, 2002), Ю. Погорелов (Pogorelov, 2011), С. Покропивный (Pokropivniy, 1999), А. Шеремет (Sheremet, 2011) и Ар. В работах этих авторов рассмотрены необходимость эффективной деятельности преАприятий как важного элемента рыночной системы, освещены методологические вопросы развития преАприятия и его оценки с точки зрения ресурсного и результатного подходов, определена совокупность показателей, которые отражают определенные изменения на предприятии и тому подобное.

Несмотря на большое количество опубликованных работ, теоретическую и практическую их ценность, немало методических аспектов проблематики требуют Аальнейших научных исследований, что определило цель исследования - преАложить теоретико-методический поАХОА к оценке уровня развития преАприятия, который основывается на взаимосвязи между факторами влияния, имАюстрирующие Аействие внутренней и внешней среАы функционирования преАприятий, и показателями уровня развития преАприятия. Четкость и маконичность в их трактовке позволит не только оценить уровень развития преАприятия в условиях глобамизации, но и на этой основе преАложить конкретные Аействия, направменные на его повышение.

\section{2. Система факторов и показателей Аля оценки уровня развития преАприятия в условиях гмобамизации}

Аеятельность преАприятия, в первую очередь, обусловлена имеющимися ресурсами, которые используются в производственном процессе, их количеством, составом и эффективностью использования. Ресурсное обеспечение потенциала преАприятия можно опредемить как совокупность основных факторов производства (материальных, технико-технологических, трудовых), что явмяется основой формирования потенциала предприятия. Самостоятельный выбор видов и направмений использования ограниченных ресурсов, что обеспечивает стремление преАприятий к постоянному развитию обусловлен конкуренцией, стимулирующие механизмы которой в гмобализационных условиях особенно усиливаются. Конкурентный тип рыночных отношений в современных условиях связан с целенаправленным стимулирующим воздействием государства на преАпринимательский сектор через использование соответствующих инструментов фискацьной, Аенежно-кредитной, антимонопольной политики. Повышение эффективности производственной Аеятельности и темпов экономического развития преАприятия в условиях глобализации возможно только за счет осуществиения преАприятиями активной инвестиционной и инновационной Аеятельности. Интегрирование экономики страны в мировое хозяйство, ее участие в различных видах межАународного сотрудничества повышает роль и значение внешнеэкономической деятельности преАприятия.

Следовательно, развитие преАприятия зависит от многих факторов, которые имююстрируют Аействие как внутренней, так и внешней среды функционирования преАприятий и такими факторами в условиях глобализации, по нашему мнению, явмяются: имеющиеся ресурсы и возможности их использования; конкуренция межАу преАприятиями на рынке; направленность госуАарственного влияния на поААержку развития преАпринимательского сектора; инвестиционно-инновационная Аеятельность преАприятия; финансово-экономическая деятельность преАприятия, внешнеэкономическая деятельность преАприятия.

Имеющиеся ресурсы и возможности их использования имююстрируются с помощью таких известных показателей, как: фондоотАача, материалоотАача и производительность труАа. Уровень конкуренции межАу преАприятиями на рынке можно выразить через Аолю предприятия на рынке. Направценность государственного влияния на поААержку развития преАпринимательского сектора характеризуется Аолей уплаченных налогов в общих затратах преАприятия (коэффициент налоговой нагрузки). Показатемями инвестиционноинновационной Аеятельности предприятия явмяется Аоля нематериальных активов и коэффициент инвестирования. Результаты финансово-экономической Аеятельности преАприятия Аемонстрируются с помощью рентабельности Аеятельности преАприятия, коэффициентов оборачиваемости активов, общей миквиАности (покрытие), финансовой устойчивости (автономии) и коэффициента Бивера. Показателями же внешнеэкономической Аеятельности преАприятия явмяется Аоля продукции на экспорт в общем объеме продукции преАприятия.

\section{3. МетОАИческИй ПОАХОА к оценке Уровня развития преАприятия в условиях гмобамизации}

Понимая, что кажАый в отАельности из указанных показателей, во-первых, не имеет всеобъемлющего характера, во-вторых, только частично отражает результативность факторов, влияющих на развитие 
преАприятия, способом решения таких ограничений считаем идентификацию интегрального показателя уровня развития преАприятия в условиях глобализации. ПослеАний способен сбалансировать, с оАной стороны, необходимость вкмючения Аостаточно большого количества аспектов развития преАприятия и чрезмерную формализацию Аанного показателя и, с Аругой стороны, возможность его практического использования А^я интегрального оценивания уровня развития как отАельных преАприятий, так и отрасли в целом.

Понятно, что уровень развития преАприятия Аолжен отображаться с помощью определенных показателей. Оценка уровня развития предприятия может быть реализована с использованием специфического показателя - интегрального показателя уровня развития преАприятий отрасли в условиях глобализации, выражающийся общеизвестной функцией Харрингтона:

$$
D=\sqrt[m]{\prod_{i=1}^{m} y_{j}},
$$

где $D$ - среднее геометрическое отАельных желательностей (частичных функций желательности $y_{j}(П)-$ показателей уровня развития преАприятия).

Пределы изменения значений обобщенной $(D)$ и частичных $\left(y_{j}\right)$ функций жекательности - $[0 ; 1]$. В основе построения этой обобщенной функции содержится идея преобразования натуральных или относительных значений критериев в безразмерную шкалу желательности в пределах от 0 до 1 , то есть формализации преАставлений исследователя о важности тех или иных значений отдельных критериев оптимальности. Эта общепринятое соответствие приведено в таблице 1.

Таблица 1

Стандартные оценки по шкале желательности

\begin{tabular}{|l|c|}
\hline \multicolumn{1}{|c|}{ Жемательность } & $\begin{array}{c}\text { Оценки по шкаме } \\
\text { желательности }\end{array}$ \\
\hline Очень хорошо & $1,00-0,80$ \\
\hline Хорошо & $0,80-0,63$ \\
\hline Уовметворительно & $0,63-0,37$ \\
\hline Плохо & $0,37-0,20$ \\
\hline Очень пиохо & $0,20-0,00$ \\
\hline
\end{tabular}

В нашем скучае преАлагаем использовать D как среАнее геометрическое отдельных показателей уровня развития преАприятия $\left(y_{j}\right)$, которые могут иметь одинаковую или разную значимость и приведены к безразмерной форме, то есть быть нормируемыми. В качестве факторов, которые вмияют на уровень развития преАприятия и выражаются соответствующими показатемями $\left(y_{j}\right)$, были выбраны следующие: фактор «Ресурсы» $-\Pi_{1}$, фактор «Финансово-экономическая Аеятельность» - $\Pi_{2}$, фактор «Инвестиционно-инновационная Аеятельность» - П , фактор «Конкуренция» $-\Pi_{4}$, фактор «Государственное вмияние» $-\Pi_{5}$, фактор «Внешнеэкономическая деятельность $>-\Pi_{6}$.

Поэтому показатель уровня развития преАприятия (ПРРП) может приобрести виА:
ПРРП $=\sqrt[6]{\Pi_{1} * \Pi_{2} * \Pi_{3} * \Pi_{4} * \Pi_{5} * \Pi_{6}}$,

гае $\Pi_{1}=\sqrt[3]{a_{1} * a_{2} * a_{3}} ; \quad \Pi_{2}=\sqrt[5]{b_{1} * b_{2} * b_{3} * b_{4} * b_{5}}$; $\Pi_{3}=\sqrt[2]{c_{1} * c_{2}} ; \Pi_{4}=f_{1} ; \Pi_{5}=k_{1} ; \Pi_{6}=s_{1}$.

Поскольку факторы, которые выражаются соответствующими показатемями П1-П3 явмяются функциями от нескольких факторов, ПРРП приобретает следующий виА:

$$
\begin{aligned}
& \text { ПРРП }=\sqrt[6]{\Pi_{1}\left(a_{1}, a_{2}, a_{3}\right) * \Pi_{2}\left(b_{1}, b_{2}, b_{3}, b_{4}, b_{5}\right) *} \\
& * \Pi_{3}\left(c_{1}, c_{2}\right) * \Pi_{4}\left(f_{1}\right) * \Pi_{5}\left(k_{1}\right) * \Pi_{6}\left(s_{1}\right)
\end{aligned}
$$

гАе $a_{1}$ - фондоотАача, $a_{2}$ - производительность труАа, $a_{3}$ - материалоотАача; $b_{1}$ - рентабельность Аеятельности, $b_{2}$ - коэффициент оборачиваемости активов, $b_{3}$ - коэффициент общей миквидности (покрытия), $b_{4}-$ коэффициент финансовой устойчивости (автономии), $b_{5}$ - коэффициент Бивера; $c_{1}$ - доля нематериальных активов, $c_{2}$ - коэффициент инвестирования; $f_{1}$ - Аоля рынка преАприятия; $k_{1}$ - коэффициент налоговой нагрузки; $s_{1}$ - Аомя продукции на экспорт в общем объеме продукции преАприятия.

\section{4. Интеграмьный показатемь уровня развития преАприятия в условиях глобамизации}

ОАной из главных заАач, возникающих переА исслеАователем при использовании интегрального показателя уровня развития предприятия явмяется нормирование значений факторов с целью избежания разноразмерности. Как правило, величины нормируются в Аиапазоне от 0 до 1. Чаще всего с этой целью применяется минейное преобразование слеАующего вида:

$$
y(x)=\frac{x-x_{\min }}{x_{\max }-x_{\min }},
$$

гАе $y(x)$ - нормированный показатель, $x$ - текущее значение фактора, $x_{\min }$ - минимальное значение фактора, $x_{\max }$ - максимальное значение фактора.

Таким образом в результате получим безразмерный показатель уровня развития преАприятия, который имеет пределы от 0 до 1. Сравнение рассчитанных значений Аанного показателя Аля разных преАприятий или отраслей Ааст возможность сАелать вывоА об уровне их развития, тогАа как его расчет в рамках отАельного преАприятия за разный промежуток времени позволит выявить тенденции прогресса (роста) или регресса преАприятия за анализируемый периоА времени.

Как отмечалось ранее, отдельные показатели, выражающие влияние факторов на уровень развития преАприятия $\left(\Pi_{1}-\Pi_{6}\right)$ могут иметь оАинаковую или разную значимость, в результате чего виА формулы Аля расчета показателя уровня развития преАприятия может быть Аругой. Введение в формулу 2 весового коэффициента (значимость факторов) Ааст возможность учитывать уровень значимости каждого фактора, который влияет на уровень развития преАприятий отрасли и выражается соответствующими показатемями. 
Показатель уровня развития предприятия может быть среАним геометрическим частных показателей $\Pi_{1}-\Pi_{6}$, которые имеют одинаковую значимость. В случае, когАа показатели имеют разную значимость Аолжна быть использована формула расчета среднего геометрического взвешенного и в этом случае формула 2 приобретает виА:

$$
\text { ПРРП }=\sqrt[\sum \mathrm{e}]{\Pi_{1}^{e_{1}} * \Pi_{2}^{e_{2}} * \Pi_{3}^{e_{3}} * \Pi_{4}^{e_{4}} * \Pi_{5}^{e_{5}} * \Pi_{6}^{e_{6}}},
$$

гАе $e_{1}, e_{2}, e_{3}, e_{4}, e_{5}, e_{6}-$ весомости (значимость факторов). Следующим этапом преАложенной методики явцяется ранжирование показателей $\Pi_{1}-\Pi_{6}$ по шкале порядка, то есть определение

их места в порядковой шкале. Место показателя в этой шкале называется рангом. Комичественное значение ранга в ряду возрастающей порядковой шкалы увеличивается от 1 до $\mathrm{m}$. Определение суммы рангов кажАого из показателей экспертной оценки и коэффициентов их весомости осуществмяется по слеАующей формуле:

$$
e_{i}=\frac{\sum_{i=1}^{n} Q_{\mathrm{i}, \mathrm{j}}}{\sum_{i=1, \mathrm{j}=1}^{n, m} Q_{\mathrm{i}, \mathrm{j}}}
$$

Ае $n$ - количество экспертов; $m$ - количество показатемей качества, которые оцениваются $(m=6) ; Q_{i, j}-$ коэффициент весомости ј-го показателя в рангах (балах), который Аам эксперт. При этом $\sum_{i=1}^{6} e_{i}=1$.

Определение весомости влияния факторов $\left(e_{i}\right)$, которые влияют на уровень развития преАприятия и выражаются через соответствующие показатели $\left(\Pi_{1}-\Pi_{6}\right)$ и их распределение Аля предоставления рангов $\left(g_{i}\right)$ в возрастающем порядке отражены в таблице 2.

Понимая, что весомость влияния каждого из факторов, выраженных соответствующими показатемями $\left(\Pi_{1}-\Pi_{6}\right)$, которые в свою очередь определены с помощью показателей $\left(a_{1}-a_{3} ; b_{1}-b_{5}, c_{1}-c_{2}, f_{1}, k_{1}, s_{1}\right)$ разная, оценить весовые коэффициенты $\left(e_{1}-e_{6}\right)$ возможно за счет мнений экспертов. Как правило, аналитические экспертные оценки преАполагают Алительную и тщательную преАварительную работу экспертов наА анализом тенАенций, оценкой состояния и путей развития объекта прогноза. Этот метоА Аает возможность в полном объеме использовать всю необходимую информацию об объекте исследова- ния, что, несомненно, повышает точность осуществцяемого прогноза. Методическим обеспечением осуществцяемого экспертного оценивания может быть анкета. Совокупность ответов Аолжна Аать полную характеристику изучаемой проблемы, и позволить установить изучаемые причинно-следственные связи.

После осуществления оценки параметров модели важным этапом явмяется проверка адекватности модели, т. е. оценки степени соответствия ее параметров характеристикам объекта иссиедования. Так, с целью определения уровня согласованности мнений экспертов, то есть проверки репрезентативности проведения экспертного оценивания целесообразным явмяется использование коэффициента конкордации $(\mathrm{W})$, который вычисмяется по формуле 7:

$$
W=\frac{12 \sum_{i=1}^{n}\left(\sum_{j=1}^{m} r_{i j}-\bar{r}\right)^{2}}{m^{2}\left(n^{3}-n\right)},
$$

гАе 12 - постоянная величина в формуле расчета коэффициента конкордации, предложенной КенАалмом; $n$ - количество показателей (в нашем случае сценариев с разными значениями $\left.x_{i}\right) ; m$ - количество экспертов; $r_{i j}$ - сумма бамлов $j$-го сценария, присвоенного ему $i$-м экспертом; $\bar{r}=\frac{1}{n} \sum_{i=1}^{n} \sum_{j=1}^{m} r_{i j}-$ среАняя сумма баммов
всех показатемей.

Расчет коэффициента конкордации Аля каждого показателя уровня развития преАприятия даст возможность определить, насколько мнения экспертов согласованы Аруг с Аругом, то есть принаАлежат к оАной генеральной совокупности оценок. Величина коэффициента конкордации может меняться в пределах от 0 Ао 1, причем его равенство еАинице означает полную согласованность мнений экспертов, а равенство нулю свидетельствует, что связи межАу оценками, полученными от разных экспертов, не существует. В случае, если $W<0,2-0,4$ согласованность экспертов явмяется слабой, а при значении Аанного коэффициента в преАелах 0,6-0,8 можно говорить о существовании сильной согласованности экспертов (Novosad, Seliverstov, 2008). В скучае сильной согласованности мнений экспертов с целью определения существенности коэффициента конкордации целесообразным в использовании явмяется критерий Пирсона $\left(\chi^{2}\right)$.

\begin{tabular}{|c|c|c|c|c|c|c|c|c|c|}
\hline \multirow{2}{*}{$\begin{array}{c}\text { Факторы, выраженные } \\
\text { показатемями }\end{array}$} & \multicolumn{7}{|c|}{ Эксперты } & \multirow{2}{*}{$\sum_{\mathrm{i}=1}^{n} Q_{\mathrm{i}, \mathrm{j}}$} & \multirow[b]{2}{*}{$e_{i}$} \\
\hline & 1 & 2 & 3 & 4 & 5 & 6 & $\mathrm{n}$ & & \\
\hline$\Pi_{1}$ & & & & & & & & & $e_{1}$ \\
\hline$\Pi_{2}$ & & & & & & & & & $e_{2}$ \\
\hline$\Pi_{3}$ & & & & & & & & & $e_{3}$ \\
\hline$\Pi_{4}$ & & & & & & & & & $e_{4}$ \\
\hline$\Pi_{5}$ & & & & & & & & & $e_{5}$ \\
\hline$\Pi_{6}$ & & & & & & & & & $e_{6}$ \\
\hline \multicolumn{8}{|c|}{$\sum_{i=1, \mathrm{j}=1}^{n, m} Q_{\mathrm{i}, \mathrm{j}}$} & & 1 \\
\hline
\end{tabular}

Таблица 2

ОпреАеление весомости вмияния факторов, которые вмияют на уровень развития преАприятия 
Vol. 2, No. 1, 2016

$$
\chi^{2}=n \cdot(m-1) \cdot W .
$$

Расчетное значение $\chi^{2}$ - критерий Пирсона сравнивается с табличным значением, если оно превышает табличное, то коэффициент конкордации существенный, а мнения экспертов явцяются согласованными. Отметим, что табличное значение критерия Пирсона с вероятностью $p=0,95$ состав яет 3,24 (Lapach, 2002). В случае превышения расчетного значения критерия Пирсона наА табличным, есть возможность усреАнения значений показателей уровня развития преАприятия в каждой точке Аля Аальнейшего расчета оптимальных границ факторов.

Определение рангов на основе синтеза мнений экспертов позволяет видоизменить формуку 5 в соответствии с установленным рангом в таблице 3 :

$$
\text { ПРРП }=\sqrt[\sum g]{\Pi_{1}^{g_{1}} * \Pi_{2}^{g_{2}} * \Pi_{3}^{g_{3}} * \Pi_{4}^{g_{4}} * \Pi_{5}^{g_{5}} * \Pi_{6}^{g_{6}}},
$$

гАе $g_{1}, g_{2}, g_{3}, g_{4}, g_{5}, g_{6}$ - ранги весомости вмияния факторов на уровень развития преАприятий отрасли, которые выражаются через соответствующие показатели.

Оптимизация зависимости уровня развития преАприятия от факторов возАействия осуществцяется с использованием обобщенного критерия оптимизации (поскольку в Аанном случае важным является соблюАение всех оптимальных числовых значений выхоАной переменной) - функции желательности Харрингтона. А^я преобразования соответствующих значений откликов $\left(y_{\mathrm{j}}\right)$ можно использовать компьютерную программу Excel и получить Аостаточное количество значений преобразования в Аолевую шкалу желательности. Из этих значений, учитывая целевую функцию - оценка уровня развития преАприятий отрасли в условиях глобализации, необходимо понимать, что в скучае значений обобщенной функции желательности Харрингтона $(D)$ в пределах желательности - очень хорошо и хорошо (в соответствующих интервалах $1,00-0,80$ и $0,80-0,63)$ уровень развития предприятия является высоким; в пределах желательности 0,37-0,63 уровень развития преАприятия явмяется среАним; в соответствующем интервале 0-0,37 уровень развития предприятия явмяется низким и, если значение меньше 0,2 уровень развития преАприятия считаем критически низким. Определения показателей уровня развития преАприятий отрасли в условиях глобализации, кото- рые преАставцяют отрасль за разный промежуток времени позволит выявить тенденции роста или регресса отрасли за анализируемый периоА времени.

Заключительным самым сложным и самым ответственным этапом Аанного моделирования явцяется анализ и интерпретация полученных результатов. Этот этап исследования завершается формулированием способов повышения уровня развития предприятия в рамках кажАого из преАложенных факторов, составляющих стратегию развития предприятия. В контексте нашего понимания сущности развития как закономерного и непрерывного процесса количественно-качественных изменений состояний функционирования предприятия в направлении достижения высшего или низшего уровней, который находится поА влиянием факторов внутренней и внешней среды преАприятия наиболее приемлемым является понимание стратегии развития преАприятия как Аолгосрочной комплексной программы конкретных Аействий на определенную перспективу, что в любом случае исключает возможность негативных количественно-качественных изменений состояний функционирования преАприятия.

В упрощенном обобщенном виде можно преАложить три виАа стратегии развития преАприятия в условиях глобализации: стратегии роста, стабильности, банкротства. Стратегия стабильности состоит в сохранении и поААержке существующих направлений Аеятельности преАприятия и Аостигнутых показателей развития преАприятия в условиях глобализации. Амя стратегии роста характерно установцение ежегодного значительного превышения интегрального показателя уровня развития преАприятия наА его значением в преАыАущем году и направленность на уцучшение частных показатемей, а в итоге интеграмьного показатемя уровня развития предприятия в условиях глобализации. Стратегия банкротства выбирается в том случае, если частичные и интегральный показатель уровня развития преАприятия явмяется настолько низким, что отсутствует возможность продлить Аеятельность из-за недостатка ресурсов, Аенежных среАств и тому подобное.

По нашему мнению, в случае значения показателя уровня развития преАприятий в пределах от 0,80 Ао 1 есть необходимость выбрать стратегию стабильности, а в преАелах от 0,63 до 0,80 - стратегию роста. При условии среА-

\section{Таблица 3}

\begin{tabular}{|c|c|c|c|c|c|c|c|c|c|c|c|c|c|}
\hline \multirow{2}{*}{$\begin{array}{c}\text { Факторы, выраженные } \\
\text { показатемями }\end{array}$} & \multicolumn{10}{|c|}{ Эксперты } & \multirow{2}{*}{$\sum_{\mathrm{i}=1}^{n} Q_{\mathrm{i}, \mathrm{j}}$} & \multirow[b]{2}{*}{$e_{\mathrm{i}}$} & \multirow[b]{2}{*}{$g_{\mathrm{i}}$} \\
\hline & 1 & 2 & 3 & 4 & 5 & 6 & 7 & 8 & 9 & 10 & & & \\
\hline$\Pi_{5}$ & & & & & & & & & & & & $e_{5}$ & $g_{5}$ \\
\hline$\Pi_{1}$ & & & & & & & & & & & & $e_{1}$ & $g_{1}$ \\
\hline$\Pi_{2}$ & & & & & & & & & & & & $e_{2}$ & $g_{2}$ \\
\hline$\Pi_{3}$ & & & & & & & & & & & & $e_{3}$ & $g_{3}$ \\
\hline$\Pi_{6}$ & & & & & & & & & & & & $e_{6}$ & $g_{6}$ \\
\hline$\Pi_{4}$ & & & & & & & & & & & & $e_{4}$ & $g_{4}$ \\
\hline & & & & & & & & & & & & $\Sigma$ & 21 \\
\hline
\end{tabular}

\section{Определение рангов весомости вмияния факторов на уровень развития преАприятия}


него уровня развития предприятия значение интегрального показателя уровня развития преАприятия может колебаться в пределах от 0,37 Ао 0,63 и сопровождается выбором стратегии роста. Если интегральный показатель уровня развития преАприятия имеет значение от 0 Ао 0,37 , уровень развития преАприятия явмяется низким и существуют возможности выбрать стратегию роста. ОАнако, если Аанный показатель меньше 0,2 уровень развития преАприятия считаем критически низким с отсутствием возможности продмить деятельность и необходимостью применить стратегию банкротства. Заметим, что кажАая из названных стратегий детализируется в выбранной Аолгосрочной комплексной программе конкретных Аействий на опредеменную перспективу.

\section{5. ВЫВОАЫ}

Следовательно, оценка уровня развития предприятия в условиях глобализации может быть осуществлена на основе такого теоретико-методического подхода, который основывается на учете взаимосвязи межАу факторами влияния, отображающих действие внутренней и внешней среАы функционирования преАприятий, и показатемями уровня развития преАприятия, которыми преАложены слеАующие: фондоотАача, произвоАительность труаа, материалоотАача, рентабельность деятельности, коэффициент оборачиваемости активов, коэффициент общей миквиАности (покрытия), коэффициент финансовой устойчивости (автономии), коэффициент Бивера, доля нематериальных активов, коэффициент инвестирования, Аоля рынка предприятия, коэффициент налоговой нагрузки, Аомя продукции на экспорт в общем объеме продукции преАприятия. В направлении реализации поАхоАа возможно использование интегрального показателя уровня развития преАприятия с помощью названных частных показателей с целью обоснования стратегии Аальнейшего развития преАприятия в условиях глобализации.

\section{References}

Andriychuk, V. (2005). Teoretyko-metodologichne obgruntuvannya efektyvnosti vyrobnyctva. Journal of Ekonomika APK, issue 1, p. 52-63.

Gontareva, I. (2012). Kategorialnyy apparat otsenivaniya effektivnosti razvitiya predpriyatiy. Journal of Ekonomika rozvitku, issue 3 (63), p. 47-54.

Ivanilov, O. (2009). Ekonomika pidpryjemstva - Kyiv, CUL, 728 p.

Lapach, S. (2002). Statistika v nauke i biznese - Kiev, Morion, 640 p.

Meyer, Marshall W. (2002). Rethinking Performance Measurement: Beyond the Balanced Scorecard. Cambridge, Cambridge University Press, $206 \mathrm{p}$.

Novosad, V., Seliverstov, R. (2008). Metodolohiia ekspertnoho otsiniuvannia - Kyiv, NADU, 48 p.

Pogorelov, Yu. (2011). Organizatsiyniy suprovid zastosuvannya sposobiv rozvitku pidpriemstva. Journal of Marketing i menedzhment innovatsiy, issue 2, p. 206-213.

Pokropivniy, S. (1999). Ekonomika pidpryjemstva - Kyiv, KNEU, 545 p.

Sheremet, A. (2011). Teoriya ekonomicheskogo analiza - Moskva, INFRA-M, 352 p.

\section{Татьяна ШВЕД}

\section{ТЕОРЕТИКО-МЕТОДИЧЕСКИЙ ПОДХОД К ОЦЕНКЕ УРОВНЯ РАЗВИТИЯ ПРЕДПРИЯТИЯ В УСЛОВИЯХ ГЛОБАЛИЗАЦИИ}

Аннотация. Предметом исследования данной статьи являются теоретико-методические и практические аспекты развития предприятий в условиях глобализации. Цель исследования - предложить теоретико-методический подход к оценке уровня развития предприятия, который основывается на взаимосвязи между факторами влияния, иллюстрирующие действие внутренней и внешней среды функционирования предприятий, и показателями уровня развития предприятия. Методика. Теоретической основой исследования стало изучение и переосмысление основных достижений мировой и отечественной науки по проблемам развития предприятий. Для достижения поставленной цели исследования применялись следующие методы: системного и структурного анализа - для формирования методических подходов к выбору факторов, влияющих на развитие предприятий; абстрактно-логический - при формулировании выводов и предоставлении предложений; метод нормирования и экспертных оценок - для реализации предложенного теоретико-методического подхода к оценке уровня развития предприятия в условиях глобализации. Результатом исследования является предложенный собственный теоретико-методический подход к оценке уровня развития предприятия в условиях глобализации, который связан с представлением развития предприятия как системы, имеющей входы - факторы, влияющие на развитие, и выходы - показатели уровня развития предприятия в пределах названных факторов. Так, факторами избраны - ресурсы, финансово-экономическая деятельность, инновационно-инвестиционная деятельность, конкуренция, государ- 
Vol. 2, No. 1, 2016

ственное влияние и внешнеэкономическая деятельность. Показателями, которые выражают названные факторы, являются - фондоотдача, производительность труда, материалоотдача в пределах первого фактора; рентабельность деятельности, коэффициент оборотности активов, коэффициент общей ликвидности, коэффициент финансовой устойчивости, коэффициент Бивера в пределах второго фактора; доля нематериальных активов, коэффициент инвестирования в рамках третьего фактора; доля рынка предприятия в общем объеме производства отрасли в рамках четвертого фактора; коэффициент налоговой нагрузки в рамках пятого фактора и доля продукции на экспорт в общем объеме продукции предприятия в рамках последнего фактора. В рамках названного подхода с целью избежания разноразмерности частных показателей, иллюстрирующих уровень развития предприятий осуществляется их нормирование. Учет весомости каждого из факторов, влияющих на уровень развития предприятия в условиях глобализации может проводиться на основе использования экспертного исследования, проверка репрезентативности которого происходит с помощью коэффициента конкордации с целью определения уровня согласованности мнений экспертов и критерия Пирсона, который подтверждает его существенность. В случае достаточной согласованности мнений экспертов есть возможность предложить интегральный показатель уровня развития предприятия в условиях глобализации на основе использования общей функции желательности Харрингтона. Оценка уровня развития предприятия в условиях глобализации для конкретной отрасли происходит с помощью общеизвестной шкалы желательности, которая находится в пределах от 0 до 1 и дает возможность вычислить интегральный показатель и определить уровень развития как высокий, средний, низкий и критически низкий. 